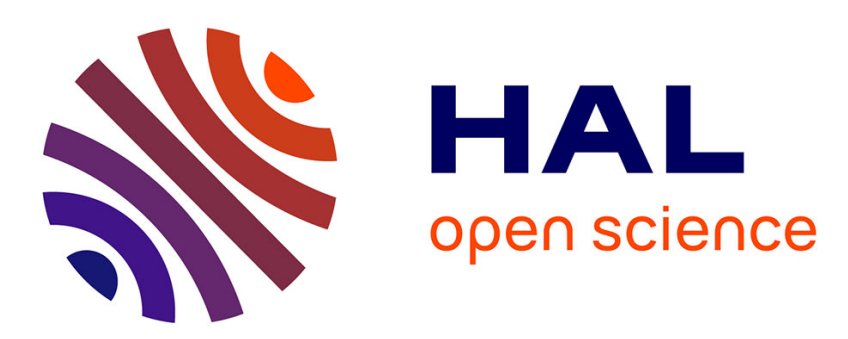

\title{
Deposition by radio frequency magnetron sputtering of GaV4S8 thin films for resistive random access memory application
}

Emeline Souchier, Marie-Paule Besland, Julien Tranchant, Benoît Corraze, Philippe Moreau, Richard Retoux, Claude Estournès, Pascale Mazoyer, Laurent Cario, Etienne Janod

\section{To cite this version:}

Emeline Souchier, Marie-Paule Besland, Julien Tranchant, Benoît Corraze, Philippe Moreau, et al.. Deposition by radio frequency magnetron sputtering of GaV4S8 thin films for resistive random access memory application. Thin Solid Films, 2013, vol. 533, pp. 54-60. 10.1016/j.tsf.2012.11.051 . hal00865622

\section{HAL Id: hal-00865622 \\ https://hal.science/hal-00865622}

Submitted on 24 Sep 2013

HAL is a multi-disciplinary open access archive for the deposit and dissemination of scientific research documents, whether they are published or not. The documents may come from teaching and research institutions in France or abroad, or from public or private research centers.
L'archive ouverte pluridisciplinaire $\mathbf{H A L}$, est destinée au dépôt et à la diffusion de documents scientifiques de niveau recherche, publiés ou non, émanant des établissements d'enseignement et de recherche français ou étrangers, des laboratoires publics ou privés. 


\section{Open Archive TOULOUSE Archive Ouverte (OATAO)}

OATAO is an open access repository that collects the work of Toulouse researchers and makes it freely available over the web where possible.

This is an author-deposited version published in : http://oatao.univ-toulouse.fr/ Eprints ID : 9372

To link to this article : DOI:10.1016/j.tsf.2012.11.051

URL : http://dx.doi.org/10.1016/j.tsf.2012.11.051

\section{To cite this version :}

Souchier, Emeline and Besland, Marie-Paule and Tranchant, Julien and Corraze, Benoit and Moreau, Philippe and Retoux, Richard and Estournès, Claude and Mazoyer, Pascale and Cario, Laurent and Janod, Etienne Deposition by radio frequency magnetron sputtering of GaV4S8 thin films for resistive random access memory application. (2013) Thin Solid Films, vol. 533 . pp. 54-60. ISSN 00406090

Any correspondance concerning this service should be sent to the repository administrator: staff-oatao@listes-diff.inp-toulouse.fr 


\title{
Deposition by radio frequency magnetron sputtering of $\mathrm{GaV}_{4} \mathrm{~S}_{8}$ thin films for resistive random access memory application
}

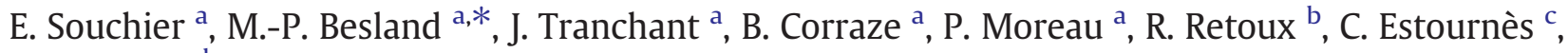 \\ P. Mazoyer ${ }^{\mathrm{d}}$, L. Cario ${ }^{\mathrm{a}}$, E. Janod ${ }^{\mathrm{a}}$ \\ a Institut des Matériaux Jean Rouxel (IMN), Université de Nantes, UMR CNRS 6502, 2 rue de la Houssinière, B.P. 32229,44322 Nantes, France \\ b CRISMAT, UMR CNRS 6508, ENSICAEN, 6 Bd Maréchal Juin, 14050 Caen Cedex 4, France \\ ' CIRIMAT, UMR CNRS 5085 - UPS - INP, 118 route de Narbonne 31062 Toulouse Cedex 4, France \\ d STMicroelectronics, 850 rue Jean Monnet, 38920 Crolles, France
}

Keywords:

$\mathrm{GaV}_{4} \mathrm{~S}_{8}$

Thin layer

RF magnetron sputtering

Sulfur material

Polycrystalline layer

XRD

Rietveld refinement

\begin{abstract}
A B S T R A C T
We report here on the deposition of $\mathrm{GaV}_{4} \mathrm{~S}_{8}$ thin layers by radio frequency (RF) magnetron sputtering in pure argon using a $\mathrm{GaV}_{4} \mathrm{~S}_{8}$ target synthesized by spark plasma sintering. Thin layers were deposited at low deposition pressure and RF power, respectively $5.33 \mathrm{~Pa}$ and $60 \mathrm{~W}$ (i.e. $3 \mathrm{~W} \mathrm{~cm}^{-2}$ ). Since as-deposited thin layers were sulfur-poor and amorphous, a one hour ex-situ annealing at $873 \mathrm{~K}$ in a sulfur-rich atmosphere was performed to restore the stoichiometric composition $\mathrm{GaV}_{4} \mathrm{~S}_{8}$ and the expected crystalline structure. Chemical analyses and high resolution transmission electron microscopy observations of thin layers are consistent with a $\mathrm{GaV}_{4} \mathrm{~S}_{8}$ phase without any secondary phase. Rietveld refinements of the X-ray diffraction (XRD) patterns confirm the good crystalline quality of the annealed deposited film constituted of crystallites exhibiting an average grain size in the 32-36 nm range. Moreover, an excellent agreement was obtained between Rietveld refinement performed on $\mathrm{GaV}_{4} \mathrm{~S}_{8}$ powder and thin films XRD data.
\end{abstract}

\section{Introduction}

During the last decades, sustained advances in integrated circuit technologies for memory and processors have given us computers with ever more powerful processing capabilities and consumer electronics with ever increasing non-volatile memory capacity [1]. Nowadays, non-volatile memories (NVM) are key components in electronic devices, and specifically nomad electronics (notebooks, cellular phones, MP3 players, numeric cameras...). Flash memory, based on charge storage in a floating-gate, is currently the leading NVM technology with more than $90 \%$ of the market. However, flash memories suffer from several drawbacks, e.g. a number of write and erase cycles limited to $10^{4}$ $10^{5}$. Moreover, as device sizes are decreasing in the sub- $100 \mathrm{~nm}$ regime, the conventional scaling methods of the semiconductor industry face increasing technological and fundamental challenges [2,3]. In particular, device size fluctuations may result in broadened variations of device characteristics at the nanoscale, affecting key parameters of the flash memory such as the threshold voltage and the on/off currents [4].

In this context, several memory concepts aiming at succeeding the flash technology have recently emerged. They range from spin-based memories (magnetic random access memories - MRAM), based on magnetic tunneling junctions [5] to phase-change RAM (PCRAM), in

\footnotetext{
* Corresponding author. Tel.: + 332403739 66; fax: + 33240373959 .

E-mail address: marie-paule.besland@cnrs-imn.fr (M.-P. Besland).
}

which thermal processes control a phase transition in the switching material from the amorphous to the crystalline state [6].

More recently, the semiconductor research community has shown a growing interest for devices based on resistive switching properties to store information. This emerging class of so-called resistive random access memories (RRAM) [7] is based on functional materials which exhibit two stable resistive states, i.e. a high resistance state, a low resistance state and a reversible non-volatile resistive switching under electric pulses. A large variety of transition metal oxides [8,9], including $\mathrm{NiO}$ $[10,11], \mathrm{TiO}_{2}[12], \mathrm{SrTiO}_{3}$ [13], manganites [14] or chalcogenides [15] as well as organic compounds $[16,17]$ have been reported to show hysteretic resistance switching in a metal-insulator-metal (MIM) configuration [6,7]. This MIM geometry, much simpler than that required for flash memories, MRAM or PCRAM, is a significant benefit in favor of RRAM technology. Further advantages are good compatibility with current complementary metal oxide semiconductor technology, high speed, low power switching and, finally, a good stability of the data retention with temperature [7]. Although RRAM have emerged only recently, published results look very promising. Switching times in the 100 ns range or less have been reported for individual oxide cells $[18,19]$. Also, high-density RRAM prototypes may present a very good endurance, supporting more than $10^{5}$ to $10^{6}$ write cycles [20,21]. Finally a data retention time of over 10 years has been extrapolated, for example, for $\mathrm{Ag} / \mathrm{GeSe}_{x}$ RRAMs [22] or $\mathrm{Cu}$-doped $\mathrm{HfO}_{2}$ thin films [23].

In recent works, we have discovered a reversible and non-volatile resistive switching on single crystals of the Mott insulator compounds 
$\mathrm{AM}_{4} \mathrm{X}_{8}(\mathrm{~A}=\mathrm{Ga}, \mathrm{Ge} ; \mathrm{M}=\mathrm{V}, \mathrm{Nb}, \mathrm{Ta} ; \mathrm{X}=\mathrm{S}, \mathrm{Se})[24,25]$. These studies indicate that the mechanism of resistive switching in $\mathrm{AM}_{4} \mathrm{X}_{8}[24,26]$ differs from those reported in the literature [6,7] Indeed, our results highlight an electric field effect which induces an electronic phase change from a Mott insulating state to a metallic-like state [25]. Such properties could thus be used for application as RRAM. Nevertheless, prior to envision any development of functional materials towards devices, two major challenges have to be tackled. The former one is to obtain thin layers of active and functional materials. The second challenge is to recover the functional properties on thin layers.

On the basis of well established know-how in deposition process and multi-layered functional structures $[27,28]$, the deposition of $\mathrm{AM}_{4} \mathrm{X}_{8}$ material in the form of thin layers has been investigated by non-reactive RF magnetron sputtering. This technique was chosen as deposition process since it is widely used in the back end of the line of the integration flow in microelectronics. Moreover, magnetron sputtering enables to deposit well-crystallized film of insulating or conducting materials, at low temperatures, over large areas, while controlling the film composition and microstructure, even for complex and multi-component materials.

Up to now, only few works dedicated to such complex chalcogenide thin layer deposition are reported in literature [29-32]. As previously reported [33], well crystallized $\mathrm{GaV}_{4} \mathrm{~S}_{8}$ thin layers were deposited using RF magnetron sputtering of a stoichiometric target. A resistive switching similar to the one observed previously on single crystals was evidenced [33] and recently improved [34].

The present paper is dedicated to a detailed study of the deposition process used to obtain $\mathrm{GaV}_{4} \mathrm{~S}_{8}$ polycrystalline thin layers. In particular, we have investigated the effect of main experimental parameters (RF power, deposition pressure, gas flux) on film characteristics for depositions performed at room temperature. Moreover, the effect of the ex-situ annealing on chemical composition and structural properties of the thin layers is described. High resolution observations by transmission electron microscopy highlight that the targeted $\mathrm{GaV}_{4} \mathrm{~S}_{8}$ crystalline phase was obtained in the form of thin layers. This paper demonstrates that $\mathrm{GaV}_{4} \mathrm{~S}_{8}$ polycrystalline thin layer can be obtained by non-reactive magnetron sputtering.

\section{Experimental details}

Prior to the deposition, a cylindrical $50 \mathrm{~mm}$ diameter dense and stoichiometric target was made by spark plasma sintering (SPS) technique [35] starting from a polycrystalline $\mathrm{GaV}_{4} \mathrm{~S}_{8}$ powder. $\mathrm{GaV}_{4} \mathrm{~S}_{8}$ powder was synthesized starting from a stoichiometric mixture of $\mathrm{Ga}_{2} \mathrm{O}_{3}$ and $\mathrm{V}_{2} \mathrm{O}_{5}$ commercial powders (@ Aldrich) heated under $\mathrm{H}_{2} \mathrm{~S}$ gas flux for $9 \mathrm{~h}$ at $1023 \mathrm{~K}$. Then, the $\mathrm{GaV}_{4} \mathrm{~S}_{8}$ powder was ball-milled down to a $3 \mu \mathrm{m}$ grain size, as determined by laser granulometry. Finally, the $50 \mathrm{~mm}$ cylindrical target was obtained by a ten minute sintering by SPS at $1023 \mathrm{~K}$ under a pressure of $75 \mathrm{MPa}(147 \mathrm{kN})$. Whereas a maximum bulk density of $70 \%$ was reached by conventional sintering techniques, a target with a density higher than $90 \%$ of the theoretical density, i.e. suitable for RF sputtering deposition, was obtained.

$\mathrm{GaV}_{4} \mathrm{~S}_{8}$ thin films were then deposited by $\mathrm{RF}$ magnetron sputtering in pure argon, using a customized reactor equipped with a 2 inch planar magnetron cathode (with a balanced magnetic field) and the home-synthesized $\mathrm{GaV}_{4} \mathrm{~S}_{8}$ target. As reported in previous works $[28,33,36]$, transfer to a thin layer of a complex ternary material is favored by soft deposition conditions, i.e. low RF power density and low pressure. Thin film depositions were thus performed with a RF power varying from 30 to $120 \mathrm{~W}$ (i.e. a power density in the 1.5 to $6 \mathrm{~W} / \mathrm{cm}^{2}$ range), without intentional heating of the substrate. $\mathrm{RF}$ power has been limited to the upper value of $120 \mathrm{~W}$, regarding the high values of self-bias target voltage in the $400-800 \mathrm{~V}$ range (as described in the following). Considering the low power density range involved, we assume that the substrate temperature remains close to room temperature during the entire deposition process. Deposition pressure was ranging from 2.5 to $8 \mathrm{~Pa}$, corresponding to a fixed argon gas flux in the $50-130 \mathrm{sccm}$ range ( $\mathrm{sccm}$ is for standard cubic centimeter per minute at STP). Thin layers were deposited on (100) silicon substrates located downstream at 2 or $5 \mathrm{~cm}$ from the target.

A 1 hour ex-situ annealing was performed in a sulfur rich atmosphere (under flowing hydrogen sulfide $\left(\mathrm{H}_{2} \mathrm{~S}\right)$ or in vacuum-sealed silica tube containing sulfur powder in excess) at temperature varying in the 673-1023 $\mathrm{K}$ range.

Surface morphology, film thickness and cross section of the films were observed by scanning electron microscopy (SEM), performed with a JEOL JSM $6400 \mathrm{~F}$, at acceleration voltages between 5 and $10 \mathrm{kV}$. The chemical composition was determined by energy dispersive spectroscopy (EDS) with a JEOL 5800-LV SEM using a PGT IMIX-PTS probe operating at $10 \mathrm{kV}$.

Atomic force microscopy (AFM) images were taken in tapping mode using a Nanoscope III from Digital Instrument, Inc., using a silicon tip with resistivity in the 0.01 to $0.02 \Omega \mathrm{cm}$ range from PPP-NCHR (Nanosensors).

The film microstructure was determined by X-ray diffraction (XRD) on a Siemens D5000 diffractometer using the $\mathrm{Cu} \mathrm{K} \alpha$ radiation $\left(\lambda=1.540598 \AA\right.$ ), in $\theta-2 \theta$ configuration for $2 \theta$ in the $10-60^{\circ}$ range, and with a 0.03 scan step. Diffraction peaks were attributed thanks to JCPDF files (\# 01-070-3602 for the $\mathrm{GaV}_{4} \mathrm{~S}_{8}$ phase).

High resolution transmission electron microscopy (HRTEM) observations were carried out with a JEOL 2010 FEG STEM microscope at an acceleration voltage of $200 \mathrm{kV}$. Electron diffraction patterns were recorded for a spot size of $300 \mathrm{~nm}^{2}$. Prior to HRTEM observations, $\mathrm{Ga}^{+}$focused ion beam (FIB Fei Strata DB 235) was used to cut and collect a thin slice of the $\mathrm{GaV}_{4} \mathrm{~S}_{8}$ films deposited on Si substrates.

\section{Results and discussions}

\subsection{Deposition process characterization}

As an initial step, the behavior of the home-synthesized target versus experimental deposition parameters was investigated. The evolution of the self-bias target voltage is plotted versus the RF power in the 30-120 W range (Fig. 1) for three chamber pressures in the deposition chamber, 2.67 Pa, 5.33 Pa, and $8 \mathrm{~Pa}$ and for different values of argon flux, i.e. 50, 100 and $130 \mathrm{sccm}$. As revealed, the self-bias target voltage is ranging from 400 to $800 \mathrm{~V}$, i.e. at relatively high values considering the low RF power in the 30-120 W range (power density in the 1.5 to $6 \mathrm{~W} \mathrm{~cm}^{-2}$ ranges). As displayed in Fig. 1, the absolute target voltage value increases strongly while increasing the RF power from 30 to $120 \mathrm{~W}$. Conversely, the target voltage depends only weakly on the deposition pressure. As shown, for lower deposition pressure ranging from 2.67 to $5.33 \mathrm{~Pa}$, the self-bias target voltage appears roughly constant for a RF power in the 30-50 W range. For $\mathrm{RF}$ power higher than $70 \mathrm{~W}$, only a weak variation is observed for the two Ar flux 130 and $100 \mathrm{sccm}$ and a deposition pressure of 2.7 Pa. For higher deposition pressure values, i.e. 5.33 and 8 Pa, after a first drop, the self-target voltage does not vary significantly for the three studied Ar flux values.

For a fixed pressure in the deposition chamber, only slight variation of the self-bias target voltage (variation lower than $10 \mathrm{~V}$ ) was observed while varying the argon flux in the 50-130 sccm range. Indeed, our deposition apparatus is not equipped with a regulated pumping valve. The deposition pressure is thus obtained by a manual adjustment of the pumping speed. In other words, the deposition pressure and the argon flux cannot be varied independently: a decrease of the argon flux systematically leads to a pressure decrease in the deposition chamber. We can conclude that the RF power is a main parameter for the $\mathrm{GaV}_{4} \mathrm{~S}_{8}$ deposition process. In our experimental conditions, the deposition pressure appears as a second order parameter for pressure value below $5 \mathrm{~Pa}$. Thus, in this study, only two 


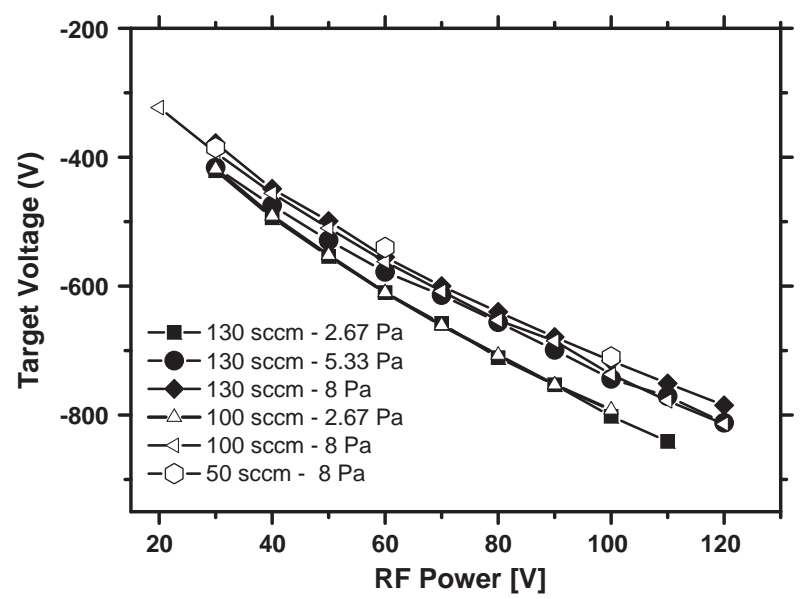

Fig. 1. Variation of the target voltage as a function of applied RF power for different pressures in the vacuum chamber: $2.67 \mathrm{~Pa}, 5.33 \mathrm{~Pa}$, and $8 \mathrm{~Pa}$ and for three argon flow values: $130 \mathrm{sccm}, 100 \mathrm{sccm}$ and $50 \mathrm{sccm}$.

main experimental parameters have been considered: RF power and deposition pressure.

\subsection{Deposition rate}

According to the process characterization previously described, the experimental parameters were investigated for two argon flux values, 50 and $100 \mathrm{sccm}$. The deposition pressure and the RF power were varied in the 1.33 to $5.33 \mathrm{~Pa}$ and 60 to $100 \mathrm{~W}$ ranges (target power density in the $3-5 \mathrm{~W} \mathrm{~cm}^{-2}$ range). Table 1 gathers a selection of samples of this study, deposited at $5.33 \mathrm{~Pa}$ and a target-to-substrate distance of $5 \mathrm{~cm}$, with their experimental conditions (RF power, Ar flux, target self-bias) and their main characteristics (thickness and chemical composition). The effect of Ar flux variation is illustrated by the comparison of samples $B$ and $C$ with samples $A$ and $D$, respectively. In both cases, the variation of the target voltage is $10 \mathrm{~V}$ and the deposition rate variation is rather weak.

For the two Ar flow rate values, the deposition rate is increasing linearly with the RF power applied to the target; no significant variation related to the flow rate value was evidenced. For a substrate-to-target distance of $5 \mathrm{~cm}$ and a deposition pressure of $5.33 \mathrm{~Pa}$, the deposition rate is varying from 3 to $6 \mathrm{~nm} \mathrm{~min}{ }^{-1}$, when the RF power is increased from 60 to $100 \mathrm{~W}$. In the studied range of experimental parameters, the higher deposition rate $\left(6 \mathrm{~nm} \mathrm{~min}{ }^{-1}\right.$ ) was obtained for a $\mathrm{RF}$ power of $100 \mathrm{~W}$, i.e. a power density of $5 \mathrm{~W} \mathrm{~cm}^{-2}$. Such low deposition rate values are indeed related to the low power density involved in the process, leading to a low sputtered species density. These values, in the $\mathrm{nm} \mathrm{min}^{-1}$ range, are in good agreement with our previous works related to complex oxides [28]. Nevertheless, $\mathrm{GaV}_{4} \mathrm{~S}_{8}$ material appeared difficult to sputter, compared to the typical deposition rate observed for magnetron sputtered materials [27,36-38].

\subsection{Chemical composition}

The chemical composition of deposited films was investigated by EDS analysis. The EDS atomic concentrations were arbitrarily normalized to the vanadium content in the stoichiometric compound $\mathrm{GaV}_{4} \mathrm{~S}_{8}$ (i.e. $\mathrm{V}$ atomic content fixed to 4) and expressed as follows: $\mathrm{x}: \mathrm{y}: \mathrm{z}$ for $\mathrm{Ga}: \mathrm{V}: \mathrm{S}$, with $\mathrm{x}, \mathrm{y}$ and $\mathrm{z}$ being the atomic content ratios $\mathrm{G} / \mathrm{V}, 4 . \mathrm{V} / \mathrm{V}$, and $\mathrm{S} / \mathrm{V}$ respectively. The chemical composition of studied deposited films is given in Table 1, for a deposition pressure of $5.33 \mathrm{~Pa}$, two RF powers (60 and $100 \mathrm{~W}$ ) and two Ar flow rates (50 and $100 \mathrm{sccm}$ ). As displayed, in the studied experimental conditions, the chemical composition $\mathrm{G}: \mathrm{V}: \mathrm{S}$ of as-deposited films is varying from 1:4:5 to 1.1:4:5.8, and the as-deposited films are thus all sulfur deficient. A RF power lower than $60 \mathrm{~W}$ and a deposition pressure lower than $2.7 \mathrm{~Pa}$ are both leading to a Ga:V ratio lower than 1:4, i.e. deposited films with lower Ga and/or low sulfur contents. We may assume that low sulfur atomic content is related to the high volatility of sulfur atoms. In addition, for low deposition pressure, the energy of ionized species is known to be higher than at higher pressure. Indeed, in low pressure conditions, the number of collisions occurring in the gas phase during the transfer of sputtered atoms between the target and the substrate is statistically lower. Such conditions could then favor a preferential re-sputtering of the deposited film, which is consistent with a sulfur deficient chemical composition.

The variation of thickness and chemical composition in the films was investigated for two values of target-to-substrate distance (2 and $5 \mathrm{~cm}$ ). The films were deposited on Si substrates $(5 \mathrm{~cm}$ length) for $2 \mathrm{~h}$ with a RF power of $60 \mathrm{~W}$, a deposition pressure of $5.33 \mathrm{~Pa}$ and an Ar flow rate of $100 \mathrm{sccm}$. For the higher target to substrate distance of $5 \mathrm{~cm}$ Fig. 2 the variation of the chemical composition, i.e. S/V and $\mathrm{Ga} / \mathrm{V}$ atomic ratios, and film thickness versus the position on the sample (i.e. over $2.5 \mathrm{~cm}$ length, starting from location just facing the target center). For this target-to-substrate distance, the thickness is varying from 400 to $300 \mathrm{~nm}$ (circle symbols) starting from the sample center, corresponding to a $25 \%$ variation. Meanwhile, the $\mathrm{Ga} / \mathrm{V}$ (open square symbols) and S/V (bold square symbols) atomic ratios are stable at 0.25 and 1.25 respectively. Compared to the targeted chemical composition ( $\mathrm{Ga}: \mathrm{V}: \mathrm{S}=1: 4: 8)$ the $\mathrm{Ga} / \mathrm{V}$ atomic ratio is equal to the targeted one, whereas the $\mathrm{S} / \mathrm{V}$ ratio is lower than expected, i.e. the films are sulfur deficient when as-deposited. For the shorter distance value $(2 \mathrm{~cm}$, not shown), the thickness varies from $1.2 \mu \mathrm{m}$ to $200 \mathrm{~nm}$, respectively in the sample center and sample edge, i.e. more than $80 \%$ variation. In the same time, the $\mathrm{Ga} / \mathrm{V}$ atomic ratio remains stable at the stoichiometric value 0.25 , whereas the $S / \mathrm{V}$ ratio is equal to 1.6 in the sample center and decreases to 1.35 at the sample edge, i.e. a $15 \%$ variation. Therefore, when the sample is located closer to the target, a high gradient is observed both for the thickness and the sulfur content, $80 \%$ and $15 \%$ respectively. The sulfur deficiency can be attributed to the higher energy of impinging species leading to a preferential loss of the most volatile element, i.e. sulfur. Such variations, especially the gradient of the chemical composition, were considered not suitable for a further study of the process. Thus, in order to investigate the most homogeneous deposited films, the target-to-sample distance value was fixed to $5 \mathrm{~cm}$ in the following of this study.

Table 1

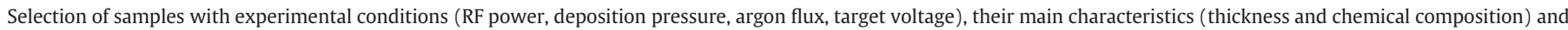
the calculated deposition rate for a target-to-substrate distance of $5 \mathrm{~cm}$.

\begin{tabular}{|c|c|c|c|c|c|c|c|c|}
\hline \multirow[t]{2}{*}{ Sample } & \multirow[t]{2}{*}{$\begin{array}{l}\text { RF power } \\
(\mathrm{W})\end{array}$} & \multirow[t]{2}{*}{$\begin{array}{l}\text { Pressure } \\
\text { (mTorr) }\end{array}$} & \multirow[t]{2}{*}{$\begin{array}{l}\text { Ar flux } \\
(\mathrm{sccm})\end{array}$} & \multirow[t]{2}{*}{$\begin{array}{l}\text { Target voltage } \\
\text { (V) }\end{array}$} & \multirow[t]{2}{*}{$\begin{array}{l}\text { Thickness } \\
(\mathrm{nm})\end{array}$} & \multirow[t]{2}{*}{$\begin{array}{l}\text { Deposition rate } \\
\left(\mathrm{nm} \mathrm{min}{ }^{-1}\right)\end{array}$} & \multicolumn{2}{|c|}{$\begin{array}{l}\text { Chemical composition } \\
\text { Ga:V:S }\end{array}$} \\
\hline & & & & & & & As deposited & After annealing \\
\hline A & 60 & 40 & 100 & -530 & 380 & 3 & $1: 4: 5$ & $1: 4: 8$ \\
\hline B & 60 & 40 & 50 & -540 & 385 & 3.2 & $0.9: 4: 5.4$ & $1: 4: 7.97$ \\
\hline C & 100 & 40 & 50 & -710 & 690 & 5.75 & $1: 4: 5.8$ & 1:4:7.95 \\
\hline $\mathrm{D}$ & 100 & 40 & 100 & -700 & 745 & 6.2 & $1: 4: 5.7$ & $1: 4: 7.9$ \\
\hline
\end{tabular}




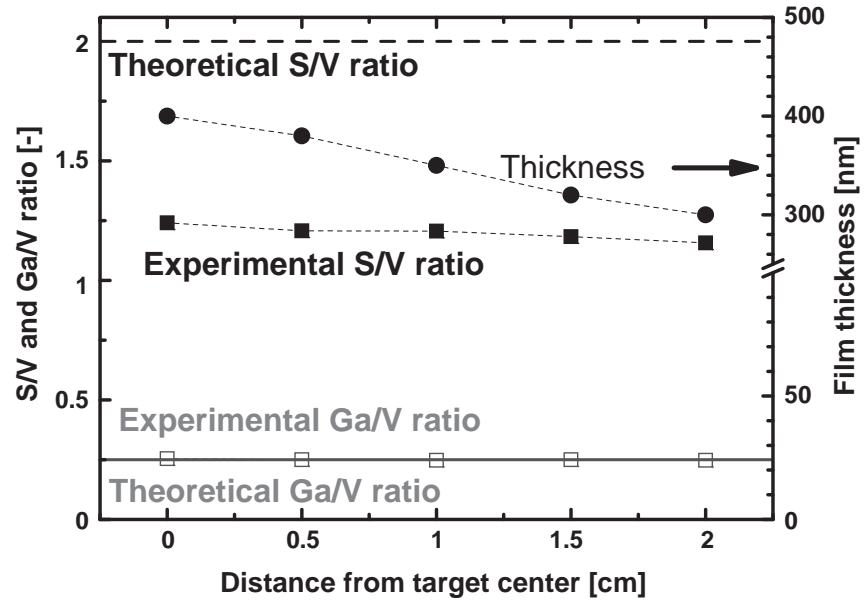

Fig. 2. Evolution of thickness (black circles and right $Y$ axis) and chemical composition $(\mathrm{Ga} / \mathrm{V}$ ratio and $\mathrm{S} / \mathrm{V}$ ratio on left $\mathrm{Y}$ axis) for a target to substrate distance of $5 \mathrm{~cm}$. The targeted values of the ratios $\mathrm{Ga} / \mathrm{V}$ and $\mathrm{S} / \mathrm{V}$ are represented in dashed lines. Sputtering conditions: RF power $60 \mathrm{~W}$, deposition pressure $5.33 \mathrm{~Pa}$, argon flow $100 \mathrm{sccm}$, deposition duration 2 h.

At this stage, we have determined a window of process parameters enabling to obtain thin films but in all cases, after the deposition step, the films were all sulfur deficient and far from the targeted chemical composition $\mathrm{GaV}_{4} \mathrm{~S}_{8}$. In the following sections, the as-deposited and non-stoichiometric films will be labeled GVS thin films.

\section{Structural characterization}

As expected, since the GVS deposited films are not stoichiometric when as-deposited, they were also amorphous, as revealed by the XRD pattern (pattern (a) in Fig. 3) where no diffraction peaks are observed. Even when the Ga:V:S expected stoichiometry is obtained, while depositing in reactive mixture $\left(\mathrm{Ar} / \mathrm{H}_{2} \mathrm{~S}\right)$, GVS thin films need to be annealed to exhibit a crystalline structure. So, amorphous as-deposited thin films were submitted to an ex-situ annealing in a sulfur rich atmosphere. Such sulfur enrichment during a post-annealing step is often reported in literature for sulfur-based films and mainly obtained thanks to sulfur powder addition $[32,39]$ or under $\mathrm{H}_{2} \mathrm{~S}$ gas flow rate [40]. Accordingly, an ex-situ annealing was performed either in a tubular furnace under hydrogen sulfide $\left(\mathrm{H}_{2} \mathrm{~S}\right)$ flux or in a sealed silica tube containing sulfur powder under a 2 Pa partial pressure. As shown in Fig. 3, both annealing

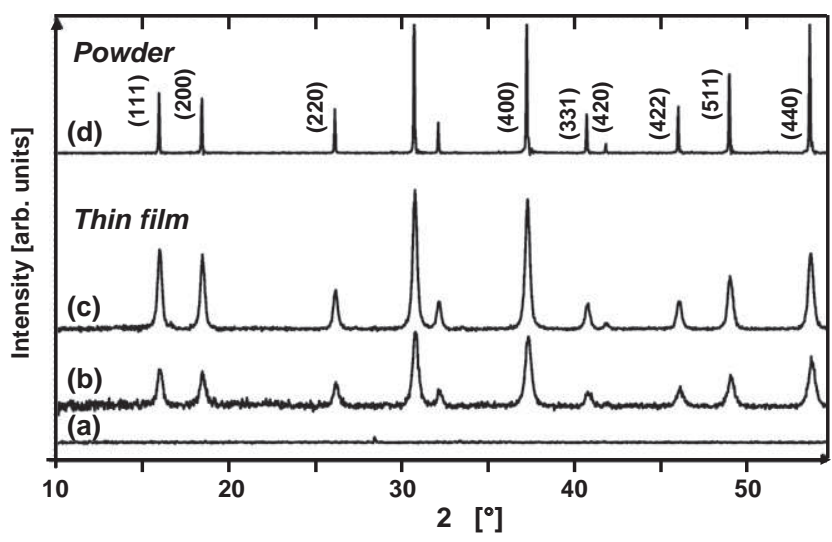

Fig. 3. X-ray diffraction patterns of a $400 \mathrm{~nm}$ thick layer after deposition (a) without annealing, (b) after $1 \mathrm{~h}$ annealing at $873 \mathrm{~K}$ in sulfur rich atmosphere in silica tube (c) under $\mathrm{H}_{2} \mathrm{~S}$ flow and (d) of a home-synthesized powder used as a reference. atmosphere, i.e. sulfur addition and $\mathrm{H}_{2} \mathrm{~S}$ flux (respectively (b) and (c) patterns in Fig. 3) lead to XRD diagrams exhibiting diffraction peaks typical of the $\mathrm{GaV}_{4} \mathrm{~S}_{8}$ phase (pattern (d) in Fig. 3) and consistent with JCPDF file no. 01-070-3602. Therefore, the expected crystalline phase is obtained after a one hour post-annealing with sulfur addition. The obtained thin films are polycrystalline and stoichiometric.

An extensive study of the effect of annealing temperature and duration time on the crystalline quality and grain size has been conducted. XRD diagrams were recorded for various annealing conditions: in the 673 to $1023 \mathrm{~K}$ and 1 to $168 \mathrm{~h}$ ranges, respectively. Rietveld refinements and calculation of the grain size with the fundamental approach were carried out using the crystallographic computing system JANA2006 (V. Petricek, M. Dusek, L. Palatinus). Fig. 4 shows the result of a typical refinement performed on a $\mathrm{GaV}_{4} \mathrm{~S}_{8}$ film submitted to a two hour annealing at $873 \mathrm{~K}$ in a sealed silica tube. This refinement confirms the good crystalline quality of the deposited film and shows that the average crystallite size is of about 32-36 nm. Moreover, the Rietveld refinements performed on both powder and thin films are in excellent agreement.

Fig. 5 shows the variation of the full width at half maximum (FWHM) of the most intense diffraction peak of the $\mathrm{GaV}_{4} \mathrm{~S}_{8}$ phase ( $(400)$ at $2 \theta \approx 37.25^{\circ}$ ) for an annealing duration of $2 \mathrm{~h}, 5 \mathrm{~h}, 48 \mathrm{~h}$ and $168 \mathrm{~h}$ at $873 \mathrm{~K}$. The annealing time is the key parameter that governs the crystallite size (Fig. 6): for annealing step at $873 \mathrm{~K}$, it increases from $35 \mathrm{~nm}$ for a $2 \mathrm{~h}$ annealing to about $70 \mathrm{~nm}$ for a longer annealing of 168 h. Conversely, we observed that the annealing temperature has less influence on the crystallite size: it remains in the $40 \mathrm{~nm}$ range for $48 \mathrm{~h}$ annealing at 400,450 or $600{ }^{\circ} \mathrm{C}$, as displayed in the inset of Fig. 6.

At this stage of the study, only a weak evolution on both grain size and crystalline quality is observed for thin films annealed for one or two hour duration. Thus a post-deposition annealing with excess of sulfur was performed for all deposited films at $873 \mathrm{~K}$ for one or $2 \mathrm{~h}$. As compared to the peak intensities of the JCPDF file for $\mathrm{GaV}_{4} \mathrm{~S}_{8}$, no variation in relative intensities of diffraction peaks was observed. We can thus conclude that in such experimental conditions, deposited and annealed films do not exhibit any preferential crystalline orientation. Furthermore, XRD patterns of annealed films exhibit diffraction peaks with higher FWHM values. As a conclusion, we can thus assume that the polycrystalline thin films of $\mathrm{GaV}_{4} \mathrm{~S}_{8}$ are constituted of grains with average size smaller than the reference powder.

Chemical compositions of the deposited films have been checked by EDS analysis after the annealing. As displayed in the last column of Table 1 , despite variations of $\mathrm{Ga} / \mathrm{V}$ and $\mathrm{S} / \mathrm{V}$ atomic ratios before annealing, the chemical composition of all thin films after the annealing

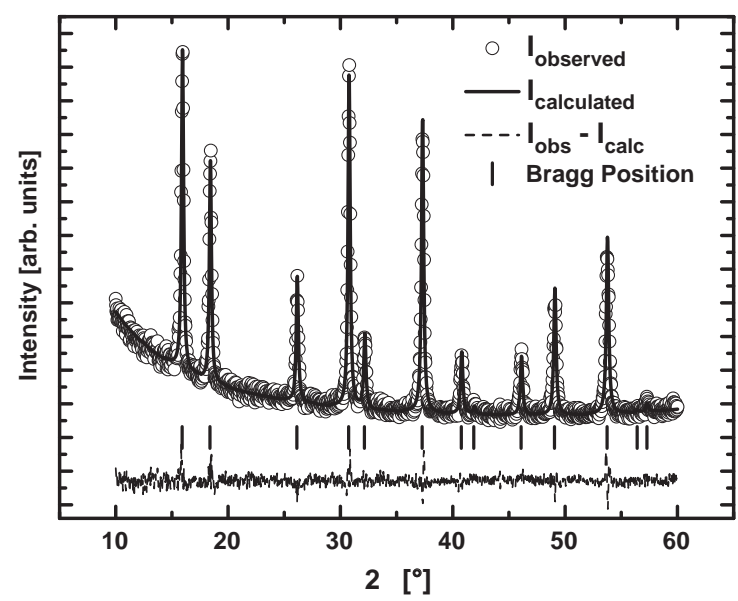

Fig. 4. Rietveld refinement of the XRD diagram of a $400 \mathrm{~nm}$ thick $\mathrm{GaV}_{4} \mathrm{~S}_{8}$ thin film annealed in a sulfur rich atmosphere (sealed silica tube) at $873 \mathrm{~K}$ for $2 \mathrm{~h}$. 


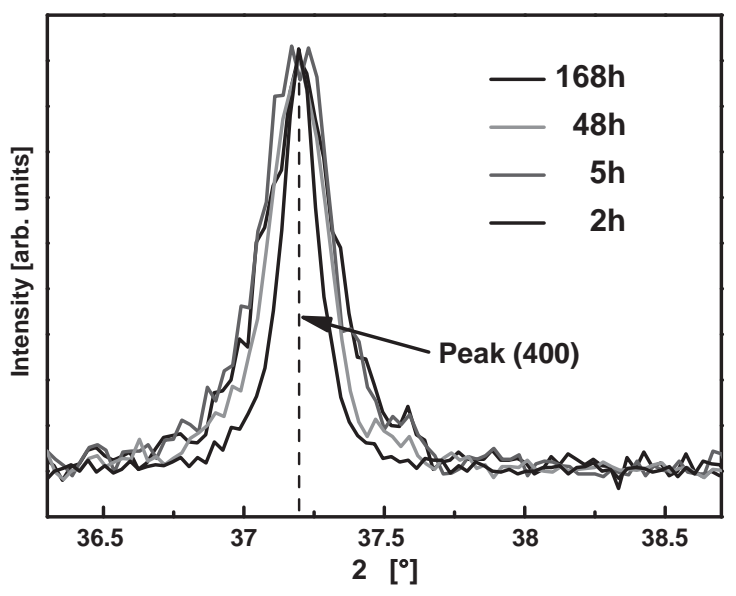

Fig. 5. Evolution of the full width at half maximum (FWHM) of the (400) diffraction peak of the $\mathrm{GaV}_{4} \mathrm{~S}_{8}$ phase (at $2 \theta \approx 37.25^{\circ}$ ) for annealing durations of $2 \mathrm{~h}, 5 \mathrm{~h}, 48 \mathrm{~h}$ and $168 \mathrm{~h}$ at $873 \mathrm{~K}$.

step is $\mathrm{GaV}_{4} \mathrm{~S}_{8}$, i.e. the expected stoichiometric chemical composition, in good agreements with XRD analysis.

\section{Morphology study by SEM and AFM}

As a next step in thin film characterizations, the morphology of the thin films was investigated before and after the annealing step. As published previously [30], the surface of thin film exhibits a granular morphology before and after annealing. SEM images of the cross section of a thin film are presented in Fig. 7. The $400 \mathrm{~nm}$ thick thin film was deposited in the following experimental conditions: RF power $60 \mathrm{~W}$, deposition pressure $5.33 \mathrm{~Pa}$, argon flow $100 \mathrm{sccm}$ and annealing $1 \mathrm{~h}$ at $873 \mathrm{~K}$ in a vacuum-sealed silica tube containing sulfur. As evidenced, a granular morphology is observed both for as-deposited film (Fig. 7a) and annealed film (Fig. 7b). An increase of the grain size was evidenced by AFM analysis in tapping mode (not shown). Before the annealing step, the average grain size is in the 15-20 nm range, whereas, after a one hour annealing step at $873 \mathrm{~K}$, it increases in the $25-30 \mathrm{~nm}$ range. These grain size values are in good agreement with the average crystallite size obtained from Rietveld calculations based on XRD patterns. In addition, the average surface roughness increases slightly from $2.3 \mathrm{~nm}$ for the as-deposited film to $3 \mathrm{~nm}$ after a one hour annealing step at $873 \mathrm{~K}$. Such a roughness value is assumed compatible with further device applications in microelectronics. Further, a thickness variation was

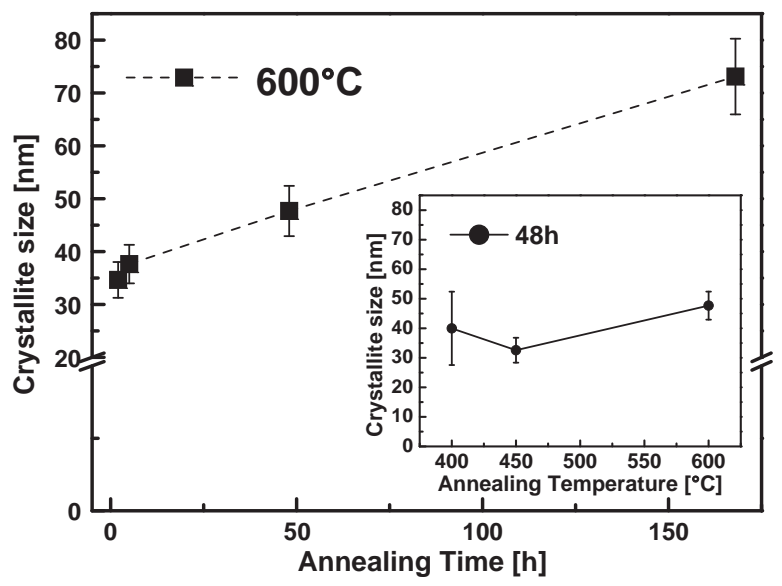

Fig. 6. Variation of crystallite size versus annealing duration at $600{ }^{\circ} \mathrm{C}$ and versus annealing temperature for $48 \mathrm{~h}$ annealing time $\left(\mathrm{GaV}_{4} \mathrm{~S}_{8}\right.$ layer thickness is $\left.400 \mathrm{~nm}\right)$. observed during the annealing step. As displayed in Fig. 7, the film thickness is decreasing from $400 \mathrm{~nm}$ (Fig. 7a) to $340 \mathrm{~nm}$ after the annealing step (Fig. 7b), leading to an average compaction of $16 \%$.

\section{HRTEM study}

To get a better insight on the bulk morphology of the films, HRTEM observations were performed on films deposited on Si substrates before and after annealing. HRTEM images of the bulk of an as-deposited and annealed film are given in Fig. 8. Fig. 8a was taken near the film surface and a complete amorphous structure is clearly evidenced. Whereas, a fine analysis at the bottom part of the film, i.e. in the first $5 \mathrm{~nm}$ near the GVS film/Si substrate interface (Fig. 8b) allows visualizing some crystalline plans exhibiting various crystalline orientations and a regular distribution in the bulk of the layer. Small crystallites of few nanometer size and various orientations are shown by the white arrows in Fig. 8b. As a conclusion, when as-deposited, GVS thin films are globally amorphous but exhibit small crystallites located $5 \mathrm{~nm}$ close to the substrate, i.e. at the very beginning of the deposition. Those crystallites are too small to be detected by XRD analysis. Nevertheless, such observation could be of great interest for a further development of the deposition process. As a last issue, HRTEM image of the bulk of a GVS film after a five hour annealing at $873 \mathrm{~K}$ is presented in Fig. 8c. The TEM analyses are in good agreement with previous characterizations. A bulk granular structure is indeed evidenced with average crystallite size in the 10 to $30 \mathrm{~nm}$ range. In the center, a $\mathrm{GaV}_{4} \mathrm{~S}_{8}$ crystallite (diameter in the $30 \mathrm{~nm}$ range) is clearly observed. The insert in Fig. 8c gives the Fourier transform of the white area of the image which reveals two inter-atomic distance values (4.9 $\AA$ and $5.5 \AA$ ), in good agreement with a $\mathrm{GaV}_{4} \mathrm{~S}_{8}$ phase. These values are well consistent with a crystalline orientation according to the (110) axis.

As published previously [33,34], the electrical properties of deposited polycrystalline $\mathrm{GaV}_{4} \mathrm{~S}_{8}$ thin layers were investigated in $\mathrm{Au} / \mathrm{GaV}_{4} \mathrm{~S}_{8} / \mathrm{Au}$ MIM structures. The variation of the thin layer resistance was investigated by applying at $300 \mathrm{~K}$ a series of $\pm 2.5 \mathrm{~V} / 10 \mu$ s pulses to the device. These results evidenced a reversible resistive switching between two resistance states with an average switching ratio $\left(R_{\text {high }}-R_{\text {low }}\right) / R_{\text {low }}$ of about $33 \%$. At this early stage of the study, a switching ratio up to 200 $300 \%$ was even observed at room temperature on the most basic $\mathrm{GaV}_{4} \mathrm{~S}_{8}$ based device. These electrical characteristics were comparable with the $1 \mu$ s writing time achieved in the most widely used flash NOR and even superior to their typical erasing times of $10 \mathrm{~ms}$. Further electrical characterizations are under progress on $\mathrm{GaV}_{4} \mathrm{~S}_{8}$ based MIM devices to determine whether this material is really competitive for further application in memory devices. In particular, works have been dedicated to the evaluation of cycling endurance, impact of downscaling on writing/ erasing speed and memory window (i.e. switching ratio $\left(R_{\text {high }}-\right.$ $\left.R_{\text {low }}\right) / R_{\text {low }}$ ) [34]. Undoubtedly, further studies are of great interest to evaluate the characteristics of $\mathrm{GaV}_{4} \mathrm{~S}_{8}$ for data storage applications.

\section{Conclusion}

$\mathrm{GaV}_{4} \mathrm{~S}_{8}$ thin films were deposited by RF magnetron sputtering process using a low power and low pressure followed by an ex-situ annealing in sulfur rich atmosphere. In our experimental conditions, the deposition process is characterized by self-bias target voltage in the 400 to $800 \mathrm{~V}$ range, i.e. relatively high values considering the involved power density range ( 1.5 to $6 \mathrm{~W} \mathrm{~cm}^{-2}$ ). As-deposited $\mathrm{GaV}_{4} \mathrm{~S}_{8}$ thin films are globally amorphous and sulfur sub-stoichiometric compared to the target composition. Nevertheless, HRTEM observations of as-deposited films evidenced small crystallites of few nanometer size and various orientations located in the first $5 \mathrm{~nm}$ close to the GVS film/Si substrate interface, i.e. at the very beginning of the deposition. Such observation could be of great interest for a further development of the deposition process. After annealing in sulfur rich atmosphere, 

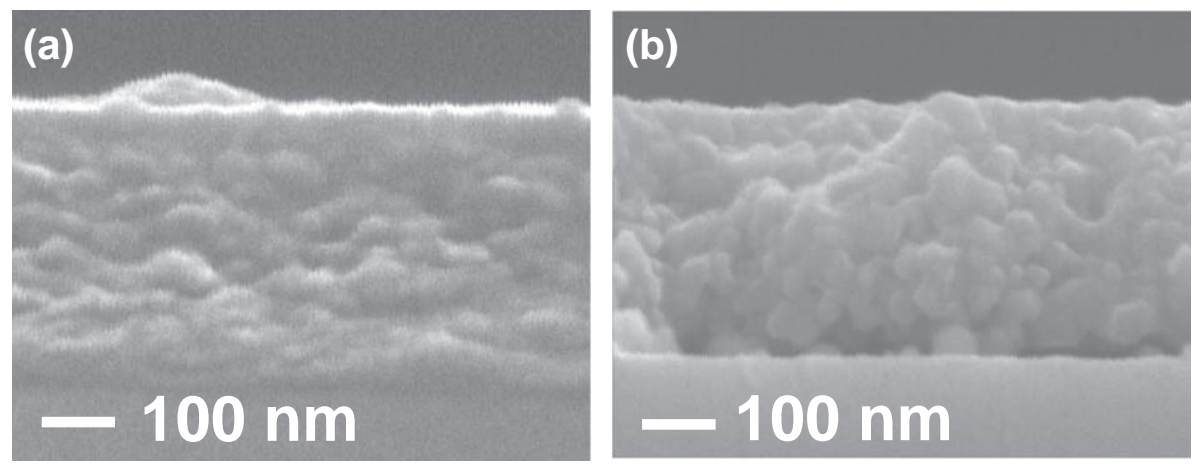

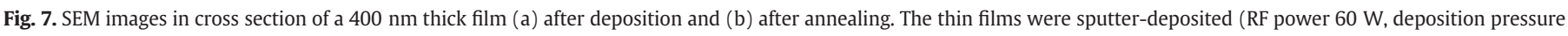
$5.3 \mathrm{~Pa}$, argon flow $100 \mathrm{sccm}$ ) and annealed in a vacuum-sealed silica tube containing sulfur in the optimal conditions (873 $\mathrm{K} / 1 \mathrm{~h}$ ).
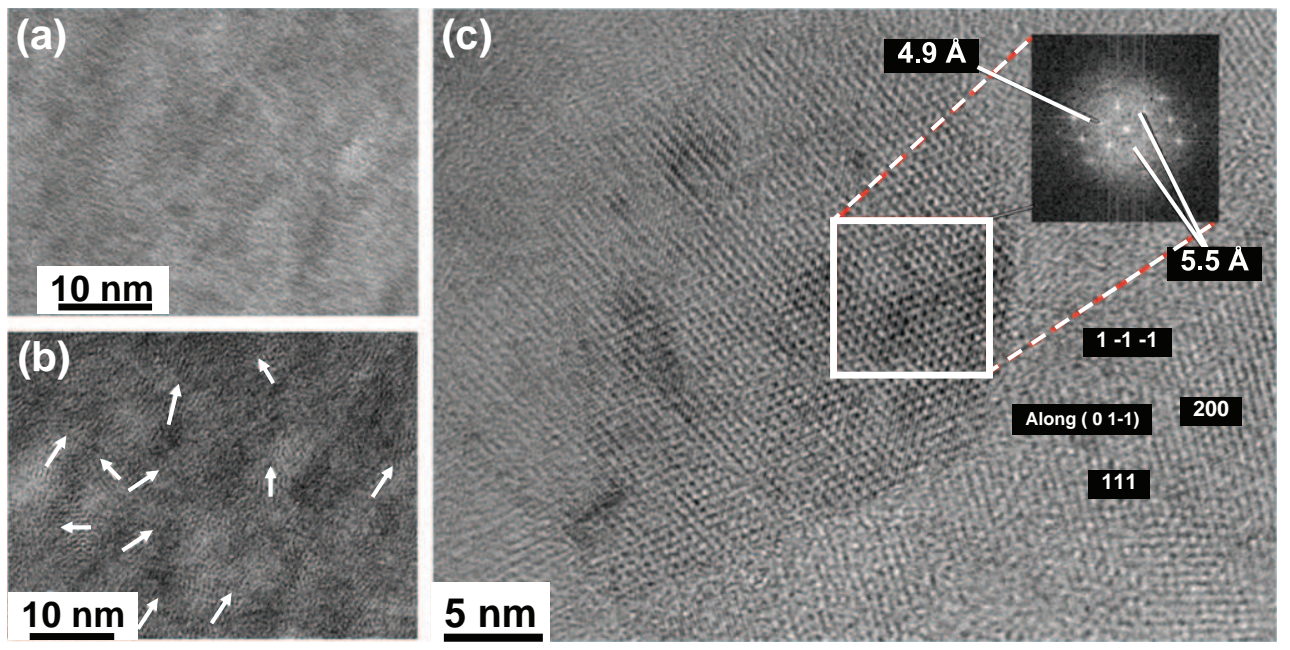

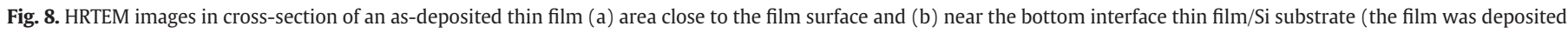

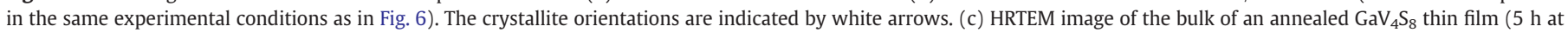
$873 \mathrm{~K})$. The inset is the Fourier transform of the red area. The measured inter-atomic distances $(0.49 \mathrm{~nm}$ and $0.55 \mathrm{~nm})$ are in good agreement with a GaV $\mathrm{S}_{8}$ phase.

the obtained layers are stoichiometric and exhibit a granular morphology. Rietveld refinements of XRD diagrams confirm that after annealing the thin films crystallize with the expected lacunar spinel structure. Moreover, these films are polycrystalline with a grain size in the 10$30 \mathrm{~nm}$ range, as characterized by HRTEM observations, AFM measurements and XRD data. Our work demonstrates the potential of these polycrystalline thin layers for RRAM non-volatile memory applications. A reversible resistive switching between two resistance states was indeed evidenced on $\mathrm{Au} / \mathrm{GaV}_{4} \mathrm{~S}_{8} / \mathrm{Au}$ MIM structures with an average switching ratio up to $200-300 \%$ at room temperature [33,34]. The observed electrical characteristics are comparable with other emerging RRAM technologies and highlight the great potential of future Mott memories based on $\mathrm{GaV}_{4} \mathrm{~S}_{8}$.

\section{Acknowledgments}

D. Troadec at IEMN (Institut d'Electronique, Micro et Nanotechnologies) from Lille (France) is gratefully acknowledged for the preparation by FIB of samples for TEM observations. Deep acknowledgments are also due to N. Stephan (Institut des Matériaux Jean Rouxel) in Nantes for SEM observations.

\section{References}

[1] ITRS, Emerging research devices, http://www.itrs.net/Links/2011ITRS/Home2011. htm.

[2] D.J. Frank, et al., Proc. IEEE 89 (2001) 259.
[3] K.K. Likharev, in: J. Greer, A. Korkin, J. Labanowski (Eds.), Nano and Giga Challenges in Microelectronics, Elsevier, Amsterdam, 2003, p. 27.

[4] R. Waser, M. Aono, Nat. Mater. 6 (11) (2007) 833.

[5] C. Chappert, A. Fert, F. Nguyen van Dau, Nat. Mater. 6 (11) (2007) 813.

[6] S. Raoux, Annu. Rev. Mater. Res. 39 (2009) 25.

[7] R. Waser, R. Dittman, G. Staikov, K. Szot, Adv. Mater. 21 (2009) 2632.

[8] A. Sawa, Mater. Today 11 (2008) 28.

[9] A. Ignatiev, N.J. Wu, X. Chen, Y.B. Nian, C. Papagianni, S.Q. Liu, J. Strozier, Phase Transitions 81 (2008) 791.

[10] J.Y. Son, Y.H. Shin, Appl. Phys. Lett. 92 (2008) 222106

[11] L. Courtade, C. Turquat, C. Muller, J.G. Lisoni, L. Goux, D.J. Wouters, D. Goguenheim, P. Roussel, L. Ortega, Thin Solid Films 516 (2008) 4083.

[12] D.S. Jeong, H. Schroeder, U. Breuer, R. Waser, J. Appl. Phys. 104 (2008) 123716.

[13] K. Szot, W. Speier, G. Bihlmayer, R. Waser, Nat. Mater. 5 (2006) 312.

[14] S. Jin, T.H. Tiefel, M. McCormack, R.A. Fastnacht, R. Ramesh, L.H. Chen, Science 264 (1994) 413.

[15] A.L. Lacaita, D.J. Wouters, Phys. Status Solidi A 205 (2008) 2281.

[16] J.C. Scott, L.D. Bozano, Adv. Mater. 19 (2007) 1452.

[17] R. Muller, C. Krebs, L. Goux, D.J. Wouters, J. Genoe, P. Heremans, S. Spiga, M. Fanciulli, IEEE Electron Device Lett. 30 (2009) 620.

[18] A. Ignatiev, N.J. Wu, X. Chen, S.Q. Liu, C. Papagianni, J. Strozier, Phys. Status Solidi B 243 (2006) 2089.

[19] D. Ielmini, C. Cagli, F. Nardi, Appl. Phys. Lett. 94 (2009) 063511.

[20] X.A. Tran, et al., IEEE Electron Device Lett. 32 (2011) 396.

[21] J. Shin, J. Park, J. Lee, et al., IEEE Electron Device Lett. 32 (2011) 958.

[22] R. Symanczyk, R. Bruchhaus, R. Dittrich, M. Kund, IEEE Electron Device Lett. 30 (2009) 876 .

[23] Y. Wang, Q. Liu, S.B. Long, et al., Nanotechnology 21 (2010) 045202.

[24] C. Vaju, L. Cario, B. Corraze, E. Janod, V. Dubost, T. Cren, D. Roditchev, D. Braithwaite, O. Chauvet, Adv. Mater. 20 (2008) 2760.

[25] C. Vaju, L. Cario, B. Corraze, E. Janod, V. Dubost, T. Cren, D. Roditchev, D. Braithwaite, O. Chauvet, Microelectron. Eng. 85 (2008) 2430.

[26] L. Cario, C. Vaju, B. Corraze, V. Guiot, E. Janod, Adv. Mater. 22 (2010) 5193.

[27] C. Duquenne, P.-Y. Tessier, M.-P. Besland, B. Angleraud, P.-Y. Jouan, R. Aubry, S. Delage, M.A. Djouadi, J. Appl. Phys. 104 (2008) 063301. 
[28] M.P. Besland, H. Djani-Ait Aissa, P.R.J. Barroy, S. Lafane, P.Y. Tessier, B. Angleraud, M. Richard-Plouet, L. Brohan, M.A. Djouadi, Thin Solid Films 495 (2006) 86.

[29] Y. Quéré, A. Perrin, R. Horyn, M. Sergent, Mater. Lett. 3 (1985) 340.

[30] J. Charrier, M.-L. Anne, T. Lhermite, V. Nazabal, J.P. Guin, F. Charpentier, T. Jouan, F. Henrio, D. Bosc, J.-L. Adam, J. Appl. Phys. 104 (2008) 073110.

[31] N. Lemée, M. Guilloux-Viry, A. Perrin, F. Lalu, J. Lesueur, Mater. Sci. Eng. B 72 (2000) 47.

[32] H. Hiramatsu, K. Ueda, H. Ohta, M. Orita, M. Hirano, H. Hosono, Thin Solid Films 411 (2002) 125.

[33] E. Souchier, L. Cario, B. Corraze, P. Moreau, P. Mazoyer, C. Estounes, R. Retoux, E. Janod, M.P. Besland, Phys. Status Solidi RRL 5 (2011) 53.

[34] J. Tranchant, E. Janod, L. Cario, B. Corraze, E. Souchier, J.-L. Leclercq, P. Cremillieu, P. Moreau, M.-P. Besland, Thin Solid Films 533C (2013-this issue) 81.
[35] C. Elissalde, M. Maglione, C. Estournes, J. Am. Ceram. Soc. 90 (2007) 973.

[36] F. Challali, M.P. Besland, D. Benzeggouta, C. Borderon, M.C. Hugon, S. Salimy, J.C. Saubat, A. Charpentier, D. Averty, A. Goullet, J.P. Landesman, Thin Solid Films 518 (2010) 4619.

[37] B. Abdallah, C. Duquenne, M.P. Besland, E. Gautron, P.Y. Jouan, P.Y. Tessier, J. Brault, Y. Cordier, M.A. Djouadi, Eur. Phys. J. Appl. Phys. 43 (2008) 309.

[38] S. Rahmane, B. Abdallah, A. Soussou, E. Gautron, P.-Y. Jouan, L. Le Brizoual, N. Barreau, A. Soltani, M.A. Djouadi, Phys. Status Solidi A 207 (2010) 1604

[39] Y.-T. Nien, S.-C. Tsai, I.-G. Chen, J. Cryst. Growth 287 (2006) 128.

[40] V. Weiss, W. Bohne, J. Röhrich, E. Strub, U. Bloeck, I. Sieber, K. Ellmer, R. Mientus, F. Porsch, J. Appl. Phys. 95 (2004) 7665. 